\title{
POLIITICA DE COMÉRCIO EXTERIOR E CRESCIMENTO INDUSTRIAL NO BRASIL
}

\author{
Arthur Barrionuevo Filho \\ Professor do Departamento de Planejamento \\ e Análise Econômica da EAESP/FGV. \\ E-mail: abarrio@eaesp.fgrsp.br
}

RESUMO: O presente trabalho faz uma revisão das características da política comercial brasileira até o final dos anos 80 e seus impactos sobre o processo de industrialização. Discute, portanto, como os ganhos e distorções da estratégia de substituição de importações foram efetivados concretamente no Brasil, destacando quais os segmentos industriais (bens de capital, insumos básicos, bens duráveis de consumo etc.) fortalecidos por esta estratégia e sua influência na crise da década de 80 .

ABSTRACT: This paper reviews the main features of industrialization and the trade policy in Brazil from the 30 s until the 80 s. It discusses how the payoffs and distortions of import substitution strategy were brought about in Brazil and which industrial sectors (capital goods, raw material, consumer goods etc.) were strengthened by it. Moreover, it reviews its influence in 80's crisis.

PALAVRAS-CHAVE: industrialização, substituição de importações, comércio exterior, políticas públicas, desenvolvimento.

KEY WORDS: industrialization, import substitution, trade, public policy, development. 
Para discutir os estímulos e as limitações gerados pela política comercial protecionista que permeou a estratégia de substituição de importações este trabalho faz primeiramente uma breve revisão das características da evolução da economia brasileira até o final dos anos 80, comparando indicadores econômicos nos períodos $1950-80$ e $1980-90$, o primeiro de rápido crescimento e, o segundo, de estagnação. Em seguida aborda especificamente a política de comércio exterior e suas distorções no Brasil durante o período de crescimento impulsionado pela industrialização protegida e no momento de crise. Finalmente, faz uma avaliação dos resultados da política de comércio exterior sobre o crescimento econômico e dos problemas trazidos por este regime de política comercial. Esta avaliação é importante para mostrar como os ganhos das empresas (lucratividade, valorização dos ativos) se altera de acordo com o dinamismo deste padrão de desenvolvimento, afetando seus objetivos em termos econômicos e de sua atuação política.

\section{RESULTADOS DA ESTRATÉGIA DE SUBSTITUIÇÃO DE IMPORTAÇÕES NO BRASIL}

A discussão suscitada pela política de comércio exterior no Brasil está intimamente vinculada à questão do desenvolvimento econômico, tendo em vista a estratégia de Industrialização de Substituição de Importações (ISI) e de suas distorções. Os trabalhos clássicos de Furtado e Tavares ${ }^{1}$ sobre a industrialização ressaltam a importância do fechamento do mercado interno ${ }^{2}$ com a crise de 1930 como o grande estímulo à produção e ao investimento industrial.

Esta visão sofreu reparos da parte de Suzigan $^{3}$ que, incorporando a visão de Dean, ${ }^{4}$ mostra como a industrialização no Brasil passou por um período de crescimento liderado pelas exportações de café, principalmente a partir dos anos 1890 até a crise de 1930, com um regime comercial bastante aberto. ${ }^{5} \mathrm{~A}$ industrialização, já nos anos 20 , começa a incorporar setores industriais de insumos intermediários e bens de capital mais leves sem alterar o regime de comércio. Nos anos 30 , o choque da depressão e consequiente colapso do comércio internacional aprofundam este processo (agora protecionista, até por falta de alternativas) com o apoio da política governa- mental que se torna industrializante no decorrer da década.

Todavia, o período que nos diz respeito é o do pós-guerra, especialmente a partir dos anos 50 , quando o protecionismo para a substituição de importações ${ }^{6}$ torna-se política de governo. O Estado assume a liderança do desenvolvimento, tanto pelo viés pró-industrialização da política econômica como pela intervenção direta, que inclui a formação de poupança forçada para acelerar a acumulação de capital, a coordenação de investimentos, a atração de empresas multinacionais e o investimento das empresas estatais na infra-estrutura básica. Nesta fase de crescimento, que se encerra em 1980, os momentos marcantes são o Plano de Metas, na segunda metade dos anos 50 , intensivo na substituição de importação de bens de consumo duráveis e de capital, o Plano de Ação Econômica do Governo (PAEG) no período pós-1964, que introduz importantes modificações institucionais (inclusive as do regime de comércio exterior) e o II PND (Plano Nacional de Desenvolvimento),que foi a resposta ao choque do petróleo incentivando a produção interna de energéticos, bens de capital e insumos básicos.

Os resultados da industrialização de substituição de importações pode ser visto na tabela 1 , na qual temos os indicadores de mudança estrutural na economia brasileira no período de 1950-80. Eles apontam um rápido crescimento econômico, o PIB (Produto Interno Bruto) per capita quadruplicado em 30 anos, uma profunda mudança na composição de atividades, com o setor secundário crescendo a $8,4 \%$ a.a. e atingindo $38 \%$ do PIB em 1980 contra $24 \%$ em 1950 e um processo de urbanização onde $51 \%$ da população vive em cidades com mais de 20.000 habitantes em 1980 comparado a $21 \%$ em 1950.

A evolução dos indicadores no período 1950-80 contrasta fortemente com os resultados da década de 80 . A estrutura econômica, medida pela composição do PIB, já havia atingido a maturidade não apresentando mudanças. O PIB per capita é declinante e o aumento na capacidade da infra-estrutura (geração de energia) deve-se muito a investimentos iniciados nos anos 70 e terminados (com atraso) durante os anos 80 . Nota-se ainda a continuidade da urbanização, que neste cenário significou piora das condições de vida nas cidades.
1. FURTADO, C. Formação econômica do Brasil. 11 ed. São Paulo: Ed. Nacional, 1971; TAVARES, M. C. Da substituição de importaçóes ao capitalismo financeiro. Rio de Janeiro: Zahar, 1975.

2. Pôde realizar esta tarefa porque foi pioneiro na recuperação de uma série para o investimento industrial no período de 1869 a 1939. A série de investimentos é construida a partir da exportação de bens de capital da Grã-Bretanha, França, Alemanha e Estados Unidos para o Brasil.

3. SUZIGAN, W. Industrialização brasileira: origem e desenvolvimento. São Paulo: Brasiliense, 1986. 0 fechamento da economia, devido à crise cambial no início dos anos 30 , incluiu 0 início do monopólio estatal das operações de comérclo exterior e a administração das importações pelo Estado em virtude da escassez de divisas, de acordo com a essencialidade das importaçóes (prioridade a insumos $e$ equipamentos vis-à-vis bens de consumo), além de uma grande desvalorização da taxa de câmbio.

4. DEAN, W. A industrialização de São Paulo. São Paulo: Difel, 1976.

5. Até os anos 30, o aumento das aliquotas aduaneiras tinha um objetivo fiscal e não 0 de aumentar a proteção.

6. O estudo deste processo produziu uma ampla bibliografia. As observações a seguir estão baseadas em SERRA, J. Ciclos e mudanças estruturais na economia brasileira do após-guerra. Revista de Economia Politica, jul. 1992, pp.111-135; BAER, $W$. The brazilian economy: growth and development. New York: Praeger Publishers, 1989; BAER W. et. alli. Structural changes in Brazil's industrial economy - 1960-80. Worid Development, February, 1987, p. 275 86; MALAN, P. BONELLI, R. The success of growth policies in Brazil. In: TEITEL, S. (ed.). Towards a new development strategy for Latin America: pathways from Hirschman's thought Washington, D.C.: Inter-American Development Bank distributed by Johns Hopkins University Press, Baltimore, 1992; para uma visão geral das mudanças estruturais, CASTRO, A.B. e SOUZA, F.E. A economia brasileira em marcha forçada. Rio de Janeiro: Paz e Terra, 1985; e FISHLOW, A. Uma história de dois presidentes: a economia política da gestão da crise. In: STEPHAN, Alfred (ed.) Democratizando o Brasil. Rio de Janeiro: Paz e Terra, 1988; sobre os resultados do II PND, DINSMOOR, J. Brazil: reponses to the debt crisis: impact on savings, investment, and growth. Washington, D.C.: Inter-American Development Bank, distributed by Johns Hopkins University Press, Baltimore, 1990. 
Tabela 1 - Indicadores de mudança estrutural

\begin{tabular}{|c|c|c|c|c|c|}
\hline \multirow[t]{2}{*}{ Indicadores \ Períodos } & \multirow[b]{2}{*}{1950} & \multirow[b]{2}{*}{1980} & \multirow[b]{2}{*}{1990} & \multicolumn{2}{|c|}{$\begin{array}{l}\text { Taxa Média de } \\
\text { Crescto. (\% a.a.) }\end{array}$} \\
\hline & & & & $1950 / 80$ & $1980 / 90$ \\
\hline 1. PIB (US\$ Bilhões de 1980) & 30 & 252 & 274 & 7.4 & 0.8 \\
\hline $\begin{array}{l}\text { 2. Composição doPIB } \\
\text { (custo de fatores) } \\
\text { - Setor primário (\%) } \\
\text { - Setor secundário (\%) } \\
\text { - Setor terciário (\%) }\end{array}$ & $\begin{array}{l}24,3 \\
24,1 \\
51,6\end{array}$ & $\begin{array}{l}10,0 \\
38,1 \\
51,9\end{array}$ & $\begin{array}{l}10,5 \\
38,6 \\
50,9\end{array}$ & $\begin{array}{l}4,1 \\
8,4 \\
7,4\end{array}$ & $\begin{array}{l}1,3 \\
1,0 \\
0,6\end{array}$ \\
\hline $\begin{array}{l}\text { 3. População (Milhões) } \\
\text { - Rural (\%) } \\
\text { - Urbano (\%) } \\
\text { - Cidades (Pop. > 20.000) (\%) }\end{array}$ & $\begin{array}{l}52 \\
64 \\
36 \\
21\end{array}$ & $\begin{array}{r}119 \\
32 \\
68 \\
51\end{array}$ & $\begin{array}{r}147 \\
25 \\
75 \\
\text { N.D. }\end{array}$ & $\begin{array}{l}2,8 \\
0,5 \\
5,0 \\
5,9\end{array}$ & $\begin{array}{r}2,1 \\
(0,6) \\
3,2 \\
\text { N.D. }\end{array}$ \\
\hline 4. PIB per capita (US\$ de 1980) & 570 & 2.080 & 1.898 & 4,5 & $(0,9)$ \\
\hline $\begin{array}{l}\text { 5. Capacidade instalada de } \\
\text { energia }(M w)\end{array}$ & 1.883 & 31.767 & 55.356 & 7,3 & 5,9 \\
\hline 6. Produção hidroelétrica (Gwh) & 5.850 & 133.767 & 228.263 & 11,0 & 5,5 \\
\hline $\begin{array}{l}\text { 7. Caminhões (milhares de } \\
\text { unidades) - Estoque no final do } \\
\text { ano }\end{array}$ & 11 & 933 & $979^{*}$ & 16,0 & N.D. \\
\hline $\begin{array}{l}8 \text {. Automóveis (milhares de } \\
\text { unidades) - Estoque no final do } \\
\text { ano }\end{array}$ & 201 & 8.156 & $9.527^{*}$ & 13,1 & N.D. \\
\hline
\end{tabular}

Obs.: (*) dados referentes a 1985, último ano em que foi feita a distinção entre os veículos automotores. Fonte: Elaborado a partir de BONELLI, R. e MALAN, P. The success of growth Policies in Brazil. In: TEITEL, S. (ed.) Towards a new development strategy for Latin America: Pathways from Hirschman's thought. Washington, D.C.: Inter-American Development Bank; distributed by Johns Hopkins University Press, Baltimore, 1992; Anuário estatístico do Brasil. Rio de Janeiro: IBGE, vários anos; ANFAVEA,1994.

7. ELIAS, V. J. Sources of growth: a study of seven latin american economies. A joint research project of the Fundacion de Tucuman and the International Center for economic growth. San Francisco: ICS Press, 1992

8. A periodização é diferente da decena seguida por Elias, para melhor adaptar-se aos ciclos do "milagre econômico", II PND, recessão 1981-83, recuperação pós1984 e recessão pós-Plano Collor I.
Referente ao crescimento acelerado no período 1940-80, um estudo recente de Elias? mostra quais foram suas fontes. $\mathrm{O}$ aumento dos fatores capital e trabalho participaram com $20,3 \%$ e $50,8 \%$ no crescimento do produto. Já a produtividade total dos fatores (PTF) participou com os $28,9 \%$ restantes. É um resultado semelhante ao de outros países em desenvolvimento, onde a contribuição da PTF para o crescimento tem em média valor em torno de $30 \%$. Na tabela 2 , podemos ver de maneira mais detalhada o crescimento dos fatores e da produtividade em subperíodos decenais. Embora a qualidade das informações não se mantenha durante todo o período, chamam a atenção os seguintes fatos: a) a queda contínua no crescimento da PTF entre 1950 e 1985 ; b) a importância do crescimento quantitativo do fator trabalho para o crescimento do produto e c) o baixo crescimento da qualidade dos fatores (em especial do capital).

Estes resultados são consistentes com o desempenho da economia brasileira entre 1980-90, quando a taxa geométrica de crescimento do produto cai para $1,6 \%$ a.a. e a taxa média de investimentos no PIB é reduzida a menos de $20 \%$. Nesta tabela é notável o declínio abrupto da acumulação de capital e trabalho entre 1980-85 em relação aos anos 70. Pior ainda, a PTF apresenta um crescimento negativo de $1 \%$ a.a.

Na tabela 3, a mesma evolução é observável ${ }^{8}$ a um nível mais micro no comportamento econômico-financeiro das empresas industriais. Através de indicadores de endividamento, liquidez corrente e rentabilidade do patrimônio, são constatados uma queda 
Tabela 2 - Taxas anuais de crescimento do PIB, dos fatores e da produtividade total dos fatores - Periodo 1940-85

\begin{tabular}{|l|c|c|c|c|c|}
\hline \multicolumn{1}{|c|}{ Itens \Período } & $\mathbf{1 9 4 0 - 5 0}$ & $\mathbf{1 9 5 0 - 6 0}$ & $\mathbf{1 9 6 0 - 7 0}$ & $\mathbf{1 9 7 0 - 8 0}$ & $\mathbf{1 9 8 0 - 8 5}$ \\
\hline 1. PIB & 5,5 & 6,8 & 5,9 & 8,2 & 1,7 \\
2. Fatores total & N.D. & 3,2 & 4,5 & 7,1 & 2,7 \\
a) Trabalho & 1,9 & 1,8 & 2,4 & N.D. & N.D. \\
- Emprego & 1,1 & 1,5 & 1,6 & 1,8 & 1,3 \\
- Qualidade & 0,8 & 0,3 & 0,8 & N.D. & N.D. \\
b) Capita & N.D. & 1,4 & 2,1 & N.D. & N.D. \\
- Bruto & N.D. & 1,5 & 2,2 & 5,3 & 1,4 \\
- Qualidade & N.D. & $-0,1$ & $-0,1$ & N.D. & N.D. \\
3. Prod. total dos fatores & N.D. & 3,6 & 1,4 & 1,1 & -1,0 \\
\hline
\end{tabular}

Obs.: N.D. = não disponível

Fonte: Elaborado a partir de ELIAS, V. J. Sources of growth: a study of seven latin american economies. A joint research project of the Fundacion del Tucuman and the International Center for economic growth. San Francisco: ICS Press, 1992.

acentuada da rentabilidade e redução do endividamento nos anos 80 e 90 . Certamente relacionados à diminuição do crescimento e menor utilização da capacidade, instabilidade macroeconômica e juros elevados.

Tabela 3 - Indicadores econômico financeiros da indústria

\begin{tabular}{|c|c|c|c|}
\hline Ano & $\begin{array}{c}\text { Endivida- } \\
\text { mento }\end{array}$ & $\begin{array}{c}\text { Liquidez } \\
\text { Corrente }\end{array}$ & $\begin{array}{c}\text { Rentab. do } \\
\text { Patr. Líquido }\end{array}$ \\
\hline $1970 \cdot 74$ & 132 & 1,43 & 19,2 \\
$1975 \cdot 80$ & 140 & 1,36 & 14,3 \\
$1981-83$ & 117 & 1,29 & 7,0 \\
$1984-89$ & 78 & 1,40 & 6,0 \\
$1990-92$ & 62 & 1,36 & 0,5 \\
\hline
\end{tabular}

Obs.: Endividamento = $($ Passivo - P.L. $) /$ P.L.; Liquidez Corrente = Ativo Circulante de C.P. / Passivo Circulante de C.P.; Rentabilidade do Patrimônio Liquido = Lucro Líquido / P.L.; C.P.: Curto Prazo;P.L.: Patrimônio Líquido.

Fonte: SERASA

\section{A POLÍTICA DE COMÉRCIO EXTERIOR NO BRASIL}

A política comercial no Brasil foi objeto de um conjunto de estudos que buscaram explicar tanto o seu impulso pró-exportações a partir dos anos 60 quanto às distorções do protecionismo. Entre estes, ressaltamos os de Coes, ${ }^{9}$ integrante de uma série de estudos sobre a liberalização do comércio externo nos países em desenvolvimento dirigida por Papageorgiou, Michaely e Choksi do BIRD, os trabalho de
Carvalho e Clements, ${ }^{10}$ que traçam um panorama das principais medidas de política comercial entre o pós-guerra e os anos 1980 e, estudos influentes como os de Tyler ${ }^{11}$ e Balassa. ${ }^{12}$

Para Coes, quando se examina a política comercial no Brasil do ponto de vista da liberalização comercial, um ponto de inflexão é o momento das reformas do pós-1964,no qual além de serem lançadas as bases da política de estímulo às exportações, se iniciou uma tímida tentativa de abertura às importações. No período anterior a este, alguns momentos devem ser destacados para se compreender a racionalidade das reformas realizadas entre 1964-67:

a) o período de $1946-52$ do imediato pósguerra, onde a crise da balança comercial gera uma resposta administrativa com controle de divisas;

b) o regime de taxas múltiplas de câmbio entre 1953-57;

c) o período posterior à reforma de $1957 \mathrm{com}$ taxa de câmbio unificada e tarifas aduaneiras ad valorem.

Durante todo o período que vai de 1946 a 1964 uma característica constante na política comercial foi a sobrevalorização cambial. Começando com o regime de 1946 , que unificou as taxas de câmbio vigentes no período de guerra, sem eliminar a sobrevalorização originada de uma taxa de câmbio nominal fixa e inflação elevada durante o conflito. E ainda, provocando queda das exportações, ${ }^{13}$ um salto de importações e queima de reservas que levaram o governo em 1947 a retornar à alo-
9. COES, D. V. Liberalizing foreign trade: the experience of Brazil. In: PAPAGEORGIOU, D.; MICHAELY, M. \& CHOKSI, A. (eds.) Lessons of experience in developing world: liberalizing foreign trade. Cambridge, Mass.: Basil Blackwell, v. 4, 1992

10. CARVALHO, J. L. Commercial policy in Brazil: an overview. In: SALAZAR CARRILLO, J. \& FENDT JR., R. (eds). The brazilian economy in the eighties. New York, Toronto, Sydney and Paris: Pergamon Press, 1985; CLEMENTS, J. C. \& MCCLAIN, J. S. The political economy of export promotion in Brazil. in. GRAHAM, L. S. \& WILSON, R. H. (eds.) The political economy of Brazil: public policies in an era of transition. Institute of Latin American studies symposia on Latin America series. Austin: University of Texas Press, 1990.

11. TYLER, W. G. Effective incentives for domestic market sales and exports: view of anti- export biases and commercial policy in Brazil, 1980-81. Journal of Development Economics, v. 18, n. 2-3, p. 219-42, August 1985; . The anti-export bias in commercial policies and export performance: some evidence from the recent brazilian experience. Weltwirtschaftliches Archiv, v. 119, n. 1 , p. $97-108,1983$;

Brazilian industrialization and industrial policies: a survey. World Development, v. 4, ก. 10 \& 11, p. 863-82, OctoberNovember 1976.

12. BALASSA, B. Incentive policies in Brazil. Worid Development, v. 7, n. 11/ 12. p. 1023-42, Nov-December 1979.

13. Entre 1946 e 1952 as exportaçōes não originadas do café sofreram uma redução de $50 \%$. 
14. Esta administração foi delegada à Carteira de Exportação e Importação (CEXIM) do Banco do Brasil.

15. CARVALHO, J. L. Op. cit

16. A existência do similar naciona obrigava a compra do produto nacional por órgãos do governo e reclassificava a tarifa aduaneira do bem na categoria especial.

17. Para Carvalho as aliquotas foram fixadas de acordo com a competição externa: 0 a $10 \%$ para os bens não produzidos no pais, 10 a $60 \%$ onde existia pouca competição e 60 a $150 \%$ onde a competição era acirrada. Cfr. CARVALHO, J. L. Commercial policy in Brazil: an overview. In: SALAZAR CARRILLO, J. Op. cação administrativa de divisas. ${ }^{14}$ Novamente, os bens essenciais e de interesse nacional receberam prioridade na compra de divisas. Em 1948 estes controles administrativos foram fortalecidos levando ao surgimento do mercado paralelo de divisas. Entretanto, com a guerra da Coréia em 1951/52, a CEXIM permitiu um aumento significativo de importações preventivas, o que ocasionou uma queda expressiva do Balanço de Pagamentos.

Em 1953, a alocação administrativa de divisas foi eliminada e substituída por cinco leilões de câmbio, de acordo com a essencialidade dos produtos importados. Os bens de capital e insumos necessários à industrialização eram classificados nas categorias II e III, e os bens já produzidos no Brasil nas categorias IV e V (supérfluos). Na mesma linha, em 1955, a Instrução 113 da Superintendência de Moeda e Crédito (SUMOC) permitiu a importação de bens de capital sem cobertura cambial para produzir bens classificados nas categorias I, II e III. Conforme Carvalho, ${ }^{15}$ as importações das categorias I a III absorviam $80 \%$ das divisas disponíveis.

Em 1957, a lei de tarifas de 1934 foi substituída por uma nova lei, a $3244 / 57$, que instituiu tarifas ad valorem (a de 1934 fixava os direitos aduaneiros em termos nominais, corroídos com a inflação), duas categorias de importados, a geral e a especial (poucos produtos) e criou a Comissão de Política Aduaneira (CPA) para administrar a lei do similar nacional. ${ }^{16}$ Como resultado, as tarifas de bens de capital e insumos foram fixadas entre 0 e $50 \%$ e a de bens de consumo entre 50 e $150 \% .17$

Entre 1961-64 a reforma de 1957 não foi mudada, contudo, $o$ alto déficit em conta corrente no Balanço de Pagamentos, devido ao serviço da dívida, gerou medidas para dificultar as importações, como os depósitos prévios do valor das importações por 150 dias (com uma taxa de juros de $6 \%$ a.a. em um regime de alta inflação) e sobretaxas para alguns bens considerados supérfluos.

As mudanças institucionais de 1964-67 tinham como um de seus objetivos básicos estabelecer uma maior importância para os mecanismos de mercado. A reforma aduaneira de março de 1967 eliminou a categoria especial de importações e cortou as taxas ad valorem para a metade do valor nominal anterior. Reduziu também a diferença de cascata entre os bens, enquanto no regime de
1957 os bens de consumo tinham alíquotas nominais cinco vezes maiores do que os bens de capital.Na reforma de 1967, esta diferença é reduzida para duas vezes. Contudo, em 1968, apesar das medidas de apoio às exportações, cresce o desequilíbrio do Balanço de Pagamentos, que somado à pressão dos produtores que se sentiram lesados, provocam o recuo da reforma de 1967. Em dezembro de 1968 foi promovida uma elevação substancial das taxas aduaneiras para os bens de consumo não duráveis, mas moderada para os bens de capital.Para Coes, a existência de um regime militar, apesar da ideologia liberal que serviu de apoio ao movimento de 1964 , permitiu as mudanças abruptas de regras, de modo que, assim como a abertura foi iniciada, decidiu-se pelo seu término. Todavia, o real motivo para o aumento significativo de importações no período foi a taxa de câmbio sobrevalorizada entre 1967-73 e não a redução de alíquotas. $O$ fracasso da abertura, entretanto, não teve uma motivação essencialmente econômica. As evidências empíricas mostram que o coeficiente de determinação (r2) entre o aumento das importações em um determinado setor e a volta da proteção no mesmo é de apenas 0,18. Mas, o r2 entre a queda da proteção e sua reversão é maior, atingindo 0,35. Portanto, a hipótese do aumento da proteção para reduzir as importações tem baixa sustentação; já a reversão de tarifas dos setores que foram atingidos pelo aumento das importações é mais significativa e pode indicar força de grupos de pressão. De outro lado, não há evidências de redução no nível de emprego ou de falências devido à maior abertura.

De qualquer modo, entre 1966-74 as importações cresceram mais rapidamente do que a produção interna, em especial nos setores de mecânica, equipamento de transporte e têxteis. Além disso, durante 1968-73, agências governamentais como a CPA, o Conselho de Desenvolvimento Industrial (CDI) e a Superintendência de Desenvolvimento do Nordeste (SUDENE) concederam uma série de reduções tarifárias para a importação de bens de capital em projetos de investimento sob sua responsabilidade. Contudo, o choque do petróleo provocou uma nova onda de restrições às importações. Em junho de 1974, o decretolei 1334/74 dobra as alíquotas de 900 produtos. Em julho de 1975 foram criados depósi- 
tos prévios (sem correção monetária) durante 6 meses sobre $100 \%$ do valor das importações . Em outubro de 1975 há um aumento de alíquotas para bens intermediários. Uma resolução da CPA, em março de 1976, baniu as importações de automóveis, brinquedos e outros bens de luxo. variação entre setores para cada ano. Até 1967 pode-se observar o efeito cascata com os bens de consumo apresentando maior proteção, seguido de bens intermediários e de capital. Podese ver também que o período da crise de endividamento externo no início dos anos 1960 é o de maior proteção efetiva. De outro lado, como

Tabela 4 - Proteção efetiva por setor (\%) - Período 1958-81

\begin{tabular}{|l|r|r|r|r|r|r|r|}
\hline & $\mathbf{1 9 5 8}$ & $\mathbf{1 9 6 3}$ & $\mathbf{1 9 6 6}$ & $\mathbf{1 9 6 7}$ & $\mathbf{1 9 7 3}$ & $\mathbf{1 9 7 5}$ & $\mathbf{1 9 8 0 - 8 1}$ \\
\hline 1. Todos os setores & 30 & 75 & 44 & 14 & 25 & 29 & N.D. \\
2. Indústria & 106 & 184 & 108 & 48 & 27 & 30 & 46 \\
- Bens de Consumo & 242 & 360 & 230 & 66 & N.D. & N.D. & 36 \\
- Bens Intermediários & 65 & 131 & 68 & 39 & N.D. & N.D. & 42 \\
- Bens de Capital & 53 & 113 & 69 & 52 & N.D. & N.D. & 72 \\
3. Setores selecionados & & & & & & & \\
- Produtos vegetais & $(47)$ & $(15)$ & $(13)$ & $(14)$ & N.D. & N.D. & $(8)$ \\
- Metalúrgica & 61 & 124 & 63 & 33 & 18 & 17 & 34 \\
- Mecânica & 22 & 68 & 30 & 31 & 9 & 13 & 93 \\
- Equip. elétr. e comunic. & 83 & 169 & 112 & 57 & 19 & 2 & 129 \\
- Equip. de transporte & 82 & 147 & 103 & 81 & 30 & 32 & $(7)$ \\
- Móveis & 221 & 367 & 251 & 92 & 44 & 42 & 53 \\
- Papel e celulose & 86 & 169 & 91 & 42 & 24 & 32 & $(19)$ \\
- Produtos de borracha & 139 & 221 & 158 & 182 & 56 & 54 & $(21)$ \\
- Química & 56 & 146 & 56 & 20 & 28 & 22 & 86 \\
- Farmacêutica & 17 & 60 & 1 & 10 & 28 & 18 & 116 \\
- Perfumes e cosméticos & 279 & 453 & 281 & 74 & 33 & 40 & 92 \\
- Produtos de plásticos & 281 & 489 & 332 & 117 & 99 & 111 & 28 \\
- Têxteis & 239 & 298 & 232 & 88 & 36 & 58 & 37 \\
- Vestuário e calçados & 264 & 481 & 321 & 154 & 26 & 32 & 47 \\
- Prod. alimentícios & 502 & 6.778 & 423 & 71 & 33 & 37 & 26 \\
\hline
\end{tabular}

Fonte:Para os valores de 1958 a 1967, FISHLOW, A. Uma história de dois presidentes: e economia política da gestão da crise. In: STEPHAN, A. Democratizando o Brasil. Rio de Janeiro: Paz e Terra, 1988; COES, D. V. Liberalizing foreign trade: the experience of Brazil. In: PAPAGEORGIOU, D. et alii. Lessons of experience in developing world: liberalizing foreign trade. Cambridge (Mass.): Basil Blackwell, v. 4, 1992.

Para os valores de 1973 e 1975, CECEX in CARVALHO, J. L.Commercial policy in Brazil: an overview. In: SALAZAR CARRILLO, J. et alii. The brazilian economy in the eighties. New York, Toronto, Sydney and Paris: Pergamon Press, 1985.

Para os valores de 1980-81, TYLER, W. G. Effective incentives for domestic market sales and exports: view of anti-export biases and commercial policy in Brazil, 1980-81. Journal of Developement Economics, v. 18, n. 2-3, p. 219-42, August 1985.

Na tabela 4 pode-se ver o impacto da estratégia de substituição de importações sobre a proteção efetiva dos setores industriais mais significativos no período de 1958-81, abrangendo assim os períodos das reformas de 1957 e 1967, da reversão de 1968 e do impacto dos dois choques do petróleo.

Embora a comparação dos resultados da tabela 4 deva ser cercada de cuidados, ${ }^{18}$ ela pode indicar tendências e permite comparações da vimos, a reforma de 1967 reduziu em média a proteção da indústria de 108 para $48 \%$.

Avaliando a estrutura setorial da proteção até o início dos anos 70 , Lowinger ${ }^{19}$ observou que o Brasil teria uma configuração semelhante à dos EUA, pois protegia mais os segmentos tradicionais intensivos em mão-de-obra nãoqualificada e menos os intensivos em capital físico e humano ${ }^{20}$,com efeitos perversos sobre a própria substituição de importações. No final dos anos 70 , conforme a estratégia do II
18. As matrizes insumo-produto não se referem ao ano da estimativa da proteção efetiva, levando a magnitudes diferentes de acordo com a matriz utilizada. A estimativa de Tyler se baseia em uma análise de equilíbrio parcial.

19. LOWINGER, T. C. Import substitution, export promotion and the structure of Brazil's protection. Journal of Development Studies, v. 10, n. 3-4, p. 430-44, April-July 1974

20. Em 1973, setores mais intensivos em capital como metalúrgica, mecânica e equipamento elétrico e de comunicações têm proteção efetiva de 18,9 e $19 \%$, ao passo que setores tradicionais como móveis, têxtil e vestuário tem proteção de 44,36 e $26 \%$, respectivamente. 
PND, a estrutura de proteção passa a privilegiar o segmento de bens de capital e intermediários vis-à-vis bens de consumo ( $72 \%$ e $42 \%$ contra $36 \%$ ). Também é notável o aumento do nível geral da proteção que se seguiu a este plano após o choque do petróleo (na indústria subindo de $30 \%$ para $46 \%$ ).

$\mathrm{O}$ alto nível de proteção e o intervencionismo pelo lado das importações tiveram sua contrapartida nos estímulos à exportação. Conforme Balassa, ${ }^{21}$ a promoção de exportações no Brasil significou sobrepor um sistema de incentivos e subsídios sobre o sistema de proteção às importações. Como já foi observado, uma característica comum ao período do pósguerra foi a sobrevalorização cambial. Contudo, várias tentativas foram feitas para incentivar as exportações. Como a taxa de câmbio nominal permanecia fixa, a CEXIM, em 1948, permitiu que parte das receitas dos exportadores fosse vendida diretamente aos importadores, ao preço oficial mais um prêmio, o que significava na prática uma certa desvalorização cambial. Este mecanismo foi suprimido em 1951 devido ao uso de divisas em importações consideradas não essenciais pelo governo. A CACEX, em 1953, além de utilizar uma taxa de câmbio diferenciado para as exportações não-tradicionais, permitiu o pagamento de um bônus aos exportadores na compra de divisas; entretanto, esta medida não foi suficiente para terminar com a sobrevalorização cambial.

O nível de exportações, portanto, permaneceu constante desde a década de 50 e era suficiente para um pequeno superávit comercial, mas não para cobrir o déficit em conta corrente. Em 1961 o governo, para tentar administrar o endividamento externo, que tinha um perfil cada vez mais de curta duração, transferiu, através da resolução 204 da SUMOC, a maioria das transações cambiais para o mercado livre, o que promoveu uma desvalorização de $40 \%$. Todavia, é a partir de 1964 que a promoção das exportações toma um caráter sistemático. Em junho deste mesmo ano, a lei 4502/64 generaliza o uso do drawback; em abril de 1965 é estabelecida a isenção do Imposto sobre Produtos Industrializados (IPI) para vendas externas; em junho de 1965, os lucros das empresas nas exportações deixam de pagar Imposto de Renda (IR) e, em fevereiro de 1967, também os Estados isentam as vendas externas do Imposto de Circulação de Mercadorias (ICM). Na tabela 5 vemos os efeitos das me- didas de incentivo, que até 1967 tinham o sentido de neutralizar os efeitos da proteção sobre as exportações.

Tabela 5 - Incentivos à exportação liberalizantes e protecionistas - Período 1963-71

\begin{tabular}{|c|c|c|}
\hline Ano & $\begin{array}{c}\text { Impostos e } \\
\text { Tarifas }\end{array}$ & $\begin{array}{c}\text { Valor Agregado } \\
\text { Unitário }\end{array}$ \\
\hline 1963 & $\begin{array}{l}\text { Tarifas, sem } \\
\text { Isençōes }\end{array}$ & $(1-t v i)-a i i(1+t v i+t i)$ \\
\hline 1964 & Drawback & $(1-t v i)-a i i(1+t v i)$ \\
\hline $1965-7$ & $\begin{array}{l}\text { Drawback } \\
\text { e Isençāo de } \\
\text { IPI e ICM }\end{array}$ & 1 - aij \\
\hline $1968-71$ & $\begin{array}{l}\text { Incentivos } \\
\text { acima mais } \\
\text { créditos de } \\
\text { IPI e ICM }\end{array}$ & $(1+s)-a i j$ \\
\hline
\end{tabular}

tvj: impostos ICM e IPI sobre o produto final “j””; aij: coeficiente unitário de insumo-produto; tvi: impostos ICM e IPI sobre o insumo " $i$ "; ti: tarifa aduaneira sobre o insumo " $i$ "; Fonte: COES, D. V. Liberalizing foreign trade: the experience of Brazil. In: PAPAGEORGIOU, D. et al. Liberalizing foreign trade. Cambridge, MA: Basil Blackwell, v. 4, 1992.

A partir do governo Costa e Silva são criados incentivos que abandonam a neutralidade da política de 1964-67, como o crédito de IPI, de julho de 1968 e o subsídio de ICM, de setembro de 1971. Além destes incentivos fiscais foram instituídos vários subsídios creditícios, como o da resolução 71/ 67 , que permitia um crédito de 120 dias para um valor de $80 \%$ das exportações com juros de $8 \%$ a.a. (bem abaixo do mercado). Em 1972 tem início o programa BEFIEX, que favorecia novos investimentos no Brasil e ainda a indústria automobilística com vantagens fiscais e de acesso à importação de insumos e equipamentos em troca de metas de exportação.

Na tabela 6 podemos ver os custos crescentes durante a década de 70 , dos subsídios para a promoção de exportações em função da sobrevalorização cambial. Pode-se observar como os incentivos apresentam tendência crescente de 1969 até 1977 , permanecendo em um nível acima de $60 \%$ do valor FOB das exportações até 1979. Em 1980, o governo procura extingui-los compensando os exportado- 
res com a maxidesvalorização de dezembro de 1979. A valorização do câmbio em 1980 provoca a necessidade do retorno dos subsídios. Todavia, na década de 80 o seu valor é declinante, seja pela nova maxi de 1983 , seja pela crise fiscal que reduz a disponibilidade de recursos. Excluindo as isenções que apenas compensam o viés pró-mercado interno, os subsídios representaram entre 1970-79, em média, 26,6\% das exportações que no mesmo período permaneceram em torno de $7 \%$ do PIB, o que significa um gasto com subsídios de quase $2 \%$ do PIB ao ano. lar americano. Além disso, conforme Tyler, ${ }^{23} \mathrm{o}$ cálculo do viés anti-exportação ${ }^{24} \mathrm{em} 1977$ para a média da indústria chegava a um valor de $43,5 \%$ (embora seu cálculo considerasse o valor de incentivos pró-exportação de apenas $24,4 \%$ ). Para o ano de $1981,{ }^{25}$ refazendo as estimativas, o viés esperado para a média de indústria é de $11,5 \%$ ( $0,7 \%$ para os bens de consumo, 7,2\% para os bens intermediários e 37\% para os bens de capital). Este último dado é mais um indicador da forte proteção que o setor de bens de capital recebeu a partir da segunda metade dos anos 70 .

Tabela 6 - Incentivos à exportação de manufaturados (como \% do valor FOB das exportações de manufaturados) - Período 1969-85.

\begin{tabular}{|c|c|c|c|c|c|c|c|c|}
\hline \multirow[t]{2}{*}{ Ano } & \multicolumn{3}{|c|}{ Isenções } & \multicolumn{4}{|c|}{ Subsídios } & \multirow{2}{*}{$\begin{array}{l}\text { TOTAL } \\
\text { GERAL }\end{array}$} \\
\hline & ICM & IPI & \begin{tabular}{|c|} 
Draw- \\
back
\end{tabular} & $\begin{array}{l}\text { Crédito } \\
\text { Prêmio } \\
\end{array}$ & $\begin{array}{c}\text { Isenção } \\
\text { I.R. }\end{array}$ & \begin{tabular}{|c|} 
Subs. \\
Crédito
\end{tabular} & $\begin{array}{l}\text { Sub- } \\
\text { Total }\end{array}$ & \\
\hline 1969 & 20,5 & 7,4 & 4,0 & 6,7 & & 4,1 & 10,8 & 42,7 \\
\hline 1970 & 20,5 & 7,2 & 4,0 & 13,5 & & 7,5 & 21,0 & 52,7 \\
\hline 1971 & 19,8 & 7,1 & 4,0 & 13,2 & 1,3 & 7,8 & 22,3 & 53,1 \\
\hline 1972 & 19,1 & 9,0 & 4,9 & 16,3 & 1,3 & 8,2 & 25,8 & 58,8 \\
\hline 1973 & 18,3 & 8,9 & 7,2 & 16,2 & 1,3 & 6,5 & 23,9 & 58,3 \\
\hline 1974 & 17,7 & 5,0 & 12,6 & 12,0 & 1,8 & 6,1 & 19,9 & 55,2 \\
\hline 1975 & 17,0 & 5,4 & 8,3 & 12,1 & 1,7 & 11,5 & 25,3 & 56,0 \\
\hline 1976 & 16,3 & 5,2 & 11,8 & 11,7 & 1,3 & 15,9 & 28,9 & 62,2 \\
\hline 1977 & 16,3 & 5,4 & 12,6 & 12,4 & 1,5 & 19,6 & 33,5 & 67,9 \\
\hline 1978 & 16,3 & 6,1 & 9,1 & 12,8 & 1,8 & 17,0 & 31,6 & 63,1 \\
\hline 1979 & 16,3 & 6,5 & 10,5 & 12,8 & 2,1 & 13,9 & 28,8 & 62,1 \\
\hline 1980 & 17,7 & 6,3 & 9,0 & 0,0 & 1,9 & 2,0 & 3,9 & 37,0 \\
\hline 1981 & 18,3 & 6,8 & 9,4 & 6,5 & 1,8 & 18,7 & 27,0 & 61,6 \\
\hline 1982 & 19,1 & 7,2 & 10,3 & 9,1 & 1,6 & 21,7 & 32,4 & 69,0 \\
\hline 1983 & 19,1 & 7,2 & 8,6 & 7,8 & 1,6 & 9,3 & 18,7 & 53,6 \\
\hline 1984 & 20,5 & 7,0 & 9,1 & 7,8 & 1,6 & 2,7 & 12,1 & 48,7 \\
\hline 1985 & 20,5 & 7,2 & 9,1 & 1,4 & 1,6 & 3,6 & 6,6 & 43,4 \\
\hline
\end{tabular}

Fonte: Bauman e Moreira (1987) in CLEMENTS, J. C. \& McCLAIN, J. S. The political economy of export promotion in Brazil. In: GRAHAM, L. S. \& WILSON, R. H. The political economy of Brazil: public policies in an era of transation. Institute of Latin American Studies Symposia on Latin America Series. Austin: The University of Texas Press, 1990.

O motivo para este valor crescente de incentivos está ligado à escolha dospolicy makers após 1974, que preferiram usar outros meios, não a taxa de câmbio para o ajuste do Balanço de Pagamentos. Para Coes, esta resistência se deve às baixas estimativas das elasticidadespreço na demanda de importações e nas exportações $^{22} \mathrm{e}$ à pouca importância dada a questões de eficiência econômica. Entre 1974-79, mesmo com as mini- desvalorizações, o cruzeiro foi valorizado cerca de $30 \%$ em relação ao dó-
Na tabela 7 pode-se constatar os efeitos das políticas comerciais no período 1950-80, quadruplicação das exportações totais, sendo que em $1950,64 \%$ das exportações brasileiras ainda eram constituídas de café. Em 1980, os produtos manufaturados já atingiam $57 \%$ do valor total e a participação do café havia sido reduzida a $13 \%$. Do lado das importações, o ano de 1980 tem um viés devido ao segundo choque do petróleo, que é indicado pela profunda depreciação dos termos de troca. Mesmo
22. Para BONELLI e MALAN, a principal resistência à desvalorização por parte do governo não dependia das elasticidades, mas do aumento do serviço da divida em Cr\$ e de pressões inflacionárias.

23.TYLER, W. G. Op. cit., 1983.

24. 0 viés anti-exportação é medido como uma diferença entre a rentabilidade das vendas nos mercados interno e externo diferença decorrente da existência de tarifas protecionistas e subsídios.

25. TYLER, W. G. Op. cit., 1985. 
26. Conforme Tavares de Araújo Jr.,durante o periodo que vai de 1950 1980 e atinge o seu apogeu com o II PND. não só o "Estado aprendeu desempenhar seu papel de agente schumpeteriano como também o empresariado descobriu os mecanismos de preservação dos benefícios que recebia". assim, ressalta se a manutenção de um nível muito reduzido das importações em relação ao PIB, pois as importações não petróleo respondiam por $6 \%$ do PIB, mesmo após três décadas de industrialização acelerada. aproximadamente metade da pauta de exportações. De outro lado, as importações - devido à política de restrições para gerar saldos comerciais - apresentaram, no mesmo período, uma redução de quantidade de $13 \%$ com

Tabela 7 - Indicadores básicos de mudanca no setor externo - Período 1950, 1980 e 1990

\begin{tabular}{|l|r|r|r|r|r|r|}
\hline & \multicolumn{2}{|c|}{1950} & \multicolumn{2}{c|}{1980} & \multicolumn{2}{c|}{1990} \\
\cline { 2 - 6 } & Valor & \% PIB & Valor & \% PIB & Valor & \% PIB \\
\hline 1. Exportações & 1.335 & 12 & 20.100 & 8 & 31.408 & 7 \\
(US\$ milhões correntes) & & & & & & \\
$\quad$ - Índice de Quantum & 100 & & 441 & & 798 & \\
- Índice de preços & 100 & & 324 & & 279 & \\
- Produtos primários (\%) & 87 & 11 & 43 & 3 & 48 & 3 \\
- Café (\%) & 64 & 8 & 13 & 1 & 4 & 0 \\
- Manufaturas (\%) & 13 & 2 & 57 & 5 & 52 & 4 \\
2. Importações & 942 & 9 & 22.955 & 9 & 20.661 & 5 \\
(US\$ milhões correntes) & & & & & & \\
- İndice de Quantum & 100 & & 447 & & 391 & \\
- Índice de preços & 100 & & 536 & & 551 & \\
- Petróleo e derivados (\%) & 15 & 1 & 42 & 4 & 23 & 1 \\
- Bens de consumo (\%) & 14 & 1 & 6 & 1 & 12 & 1 \\
- Bens intermediários (\%) & 41 & 3 & 34 & 3 & 44 & 2 \\
- Bens de capital (\%) & 31 & 3 & 19 & 2 & 19 & 1 \\
3. Termos de troca (1950 = 100) & 100 & & 61 & & 50 & \\
& & & & & & \\
4. Poder de compra das & 100 & & 267 & & 397 & \\
exportações (1950 = 100) & & & & & & \\
\hline
\end{tabular}

Fonte: BONELLI, R. e MALAN, P. The success of growth policies in Brazil. In: TEITEL, S. Towards a new development strategy for Latin America: pathways from Hirschman's thought. Washington, D. C.: Inter-American Development Bank; distribute by Johns Hopkins Univesity Press, Baltimore, 1992; Banco Central do Brasil; Comissão Econômica para a América Latina. Anuário Estatústico da America Latina. Santiago: CEPAL, 1993.

No período $1980-90$, quando a política econômica foi praticamente dominada pelos objetivos de equilíbrio no Balanço de Pagamentos (especialmente até 1984/85) e estabilização (na segunda metade dos anos 80 ), a política comercial teve sempre uma visão de curto prazo com a sua prioridade variando de acordo com o problema de política econômica mais premente. Entre as conseqüências deste tipo de condução, conforme a tabela 7, chama a atenção, do lado das exportações, que o índice de quantidade apresentou um acréscimo de $80 \%$, de 441 para 798, significando, entretanto, um aumento do poder de compra das exportações de apenas $48 \%$. O motivo foi a queda dos preços internacionais de bens primários na década de 80 , que representavam os preços aproximadamente constantes. Sua participação no PIB caiu aproximadamente pela metade.

\section{AVALIAÇÃO DOS RESULTADOS DA POLÍTICA INDUSTRIAL E DE COMÉRCIO EXTERIOR}

Uma análise final da política industrial e de comércio exterior a partir dos anos 50 deve ressaltar alguns pontos chaves. $\mathrm{O}$ primeiro é o extremo intervencionismo estatal, seja através da proteção e da redução do custo do investimento, seja através dos incentivos às exportações. Abrindo um enorme campo para o rent seeking, ${ }^{26}$ tanto para o retorno do investimento nas vendas para o mercado inter- 
no como nas exportações. ${ }^{27}$ Assim, mesmo a redução da alíquota nominal média entre janeiro de 1969 e novembro de 1973 de $66 \%$ para $57 \%$ apontada por Tyler ${ }^{28}$ como exemplo de liberalização dificilmente pode ser considerada como tal. Em primeiro lugar, pelo retrocesso de 1968 , onde houve recuo na redução das alíquotas de importação de bens de consumo. Em segundo, porque mesmo a redução apontada basicamente para bens de capital dependia de negociações administradas por projeto com órgãos como CDI, CPA, SUDENE e SUDAM não caracterizando liberalização. observável "quão pouco, em nível agregado, pode ser esperado de substituição adicional de importações". 30

Em 1979, apenas nos setores de mecânica e material elétrico e de comunicações as importações respondiam por valores significativamente acima de $10 \%$ no total do consumo; mesmo assim, abaixo de $20 \%$ do total. A redução da importação de equipamentos (mecânica e material elétrico) e insumos básicos (química e siderurgia) durante os anos 70 é uma conseqüência direta do II PND. Ela também pode ser observada na análise de Suzigan (ver tabela 9) sobre os projetos de investimento aprovados pelo CDI.

Tabela 8 - Exportação e importação de manufaturados por setor - Período 1971 e 1979

\begin{tabular}{|l|c|c|c|c|}
\hline \multirow{2}{*}{$\begin{array}{c}\text { Selotores } \\
\text { selecionados }\end{array}$} & \multicolumn{2}{c|}{$\begin{array}{c}\text { Exportaçōes } \\
\text { s/Produto (\%) }\end{array}$} & \multicolumn{2}{c|}{$\begin{array}{c}\text { Importaçóes } \\
\text { s/Oferta (\%) }\end{array}$} \\
\cline { 2 - 5 } & $\mathbf{1 9 7 0}$ & $\mathbf{1 9 7 9}$ & $\mathbf{1 9 7 0}$ & $\mathbf{1 9 7 9}$ \\
\hline - Minerais não-metálicos & 0,8 & 1,8 & 2,7 & 2,4 \\
- Metalúrgica & 3,2 & 3,7 & 10,0 & 4,6 \\
- Mecânica & 3,6 & 14,2 & 28,4 & 19,5 \\
- Equip. elétr. e comunic. & 1,4 & 4,4 & 18,8 & 14,1 \\
- Equip. de transporte & 0,7 & 9,9 & 7,8 & 3,6 \\
- Móveis & 0,3 & 0,8 & 0,1 & 0,1 \\
- Papel e celulose & 0,9 & 7,7 & 8,6 & 4,9 \\
- Produtos de borracha & 0,9 & 3,4 & 2,9 & 4,4 \\
- Química & 5,7 & 11,4 & 15,6 & 11,8 \\
- Farmacêutica & 0,8 & 2,5 & 6,0 & 8,1 \\
- Perfumes e cosméticos & 0,2 & 1,1 & 2,2 & 1,2 \\
- Produtos de plásticos & 0,1 & 0,8 & 0,5 & 0,3 \\
- Têxteis & 7,4 & 6,5 & 0,6 & 0,6 \\
- Vestúrio e calçados & 1,0 & 7,4 & 0,8 & 0,3 \\
- Prod. alimentícios & 13,3 & 16,9 & 0,9 & 5,1 \\
- Fumo & 11,5 & 22,1 & 0,0 & 0,1 \\
& & & & \\
Total da indústria & 5,7 & 9,1 & 8,0 & 6,8 \\
\hline
\end{tabular}

Fonte: Elaborado a partir de LIM, Y. Comparing Brazil and Korea. In: NAYA, S. et alii. Lessons in development: a comparative study of Asia and Latin America. Panama and San Francisco: Institute for Contemporary Studies, International Center for Economic Growth, 1989.

Um segundo aspecto a ressaltar é o esgotamento do processo de substituição de importações e, portanto, da política industrial. Como nota Tavares de Araújo Jr., "a noção de política industrial se restringia à definição de novos setores a serem implantados no país; (...) e o horizonte de médio prazo da política industrial era delimitado pela composição da pauta de importações. $O$ governo Geisel aniquilou ambos, ao completar o desenho da estrutura industrial da economia". ${ }^{29} \mathrm{Na}$ tabela 8 é
No início dos anos 80 , com a crise da dívida e um controle burocrático ainda maior sobre as importações (como o retorno da lei do similar, os programas de importação por empresa, o anexo $\mathrm{C}$ da CACEX etc.), dados da FIESP mostram que a parcela de insumos importados por unidade de produto caiu de maneira acentuada, de $15,2 \%$ em 1980 para 7,7\% em 1983. ${ }^{31}$

Toda esta proteção, aliada à oligopolização dos mercados, tiveram ainda nos anos $70 \mathrm{um}$ grande impacto sobre a rentabilidade das em-
27. Clements e McClain analisando a concentração das exportaçōes brasileiras mostram que, entre $1981-85,75 \%$ das exportaçoes eram realizadas por 250 firmas (inclusive trading companies). Além disso, entre as firmas que receberam subsídios à exportação, aquelas com faturamento anual de até $\mathrm{C}$ \$ 100 milhōes em 1978 (pequenas e médias) eram responsáveis por $10,5 \%$ das exportações e $9 \%$ dos subsídios enquanto as grandes, com faturamento acima de $\mathrm{Cr} \$ 100$ milhöes, respondiam por $89,5 \%$ das vendas e $91 \%$ do subsidio. Cfr. CLEMENTS \& McCLAIN The political economy of export promotion in Brazil. In: GRAHAM, L.S (ed.) The political economy of Brazil. public policies in an era of transition Institute of Latin American Studies Symposia on Latin America Series. Austin: University of TexasPress, 1990.

\section{TYLER, W. G. Op. cit.}

29. TAVARES DE ARAÚJO JR., J. Uma estratégia não-liberal para a abertura da economia brasileira. IEI/UFRJ (Texto para Discussão n.255), 1991. A polltica de importações: autarquia ou eficiência? Fundação Centro de Estudos do Comércio Exterior (Texto para discussão interna n²6), s.d.

30. BACHA, E. L. External shocks and growth prospects: the case of Brazil, 1973-89. World Development, v. 14, n. 8 (Special Issue), p. 919-36, August 1986.

31. DINSMOOR, J. Op. cit. 
32. LIM, Y. Comparing Brazil and Korea In: NAYA, S. et alli. (eds.) Lessons in development: a comparative study of Asia and Latin America. Panama and San Francisco: Institute for Contemporary Studies, International Center for Economic Growth, 1989.

33. MONTEIRO, J. V. et alii. A política industrial no Brasil no início da década de 80: um estudo de identificação. Pesquisa e Planejamento Econômico. v. 16, n. 2 p. 425-66, August 1986 .

34. A análise de McDonough sobre as prioridades das elites brasileiras no início da década de 70 mostra que para seus segmentos empresarial e tecnocrátic (altos funcionários governamentais) 0 crescimento econômico è um objetivo muito mais importante do que o desenvolvimento social ou a democratizaçăo.
Tabela 9 - Participação das importações de máquinas e equipamentos nos projetos aprovados pelo CDI - Período 1971-79

\begin{tabular}{|r|c|}
\hline \multicolumn{1}{|c|}{ Ano } & $\begin{array}{c}\text { \% das importaçōes } \\
\text { na oferta total }\end{array}$ \\
\hline $1971-73$ & 67,0 \\
1974 & 55,8 \\
1975 & 47,8 \\
1976 & 43,0 \\
1977 & 23,1 \\
1978 & 24,1 \\
1979 & 18,9 \\
\hline
\end{tabular}

Fonte: SUZIGAN, W. Industrialização brasileira: origem e desenvolvimento. São Paulo: Brasiliense, 1986.

presas. Lim $^{32}$, comparando o grau de competição no Brasil e na Coréia, ressalta que em nosso país a concentração industrial em cada mercado era muito mais elevada. Como conseqüência, no ano de 1979, para uma amostra significativa de empresas, o lucro líquido sobre vendas era de $6,2 \%$ no Brasil e $1,5 \%$ na Coréia enquanto o lucro líquido sobre ativos era de $5,9 \%$ e $1,9 \%$, respectivamente, embora as vendas sobre ativos de 1,24 fossem maiores na Coréia do que os 0,95 observados no Brasil. Ou seja, as empresas brasileiras tinham margens aproximadamente três a quatro vezes maiores do que as coreanas, embora um menor turnover. Deve-se observar ainda que esta é apenas parte da diferença, pois a parcela de "ineficiência X" (ou folga organizacional) não é apreendida por estes indicadores.

Esta situação agravou-se na primeira metade dos anos 80 , pois a política econômica do governo Figueiredo (1979-85) esteve voltada essencialmente para questões de curto prazo, em especial, a crise do Balanço de $\mathrm{Pa}$ gamentos e a estabilização, o que, como vimos, tornou o controle das importações ainda mais rígido. A busca do equilíbrio externo via geração de saldos comerciais foi totalmente dominada pelos resultados de curto prazo, não importando o aumento das distorções e a ineficiência provocados pelo controle burocrático das importações nem a avaliação do custo da promoção das exportações.

Segundo Monteiro et alii, ${ }^{33}$ a política industrial e de comércio exterior, preocupada com o longo prazo, neste período praticamente parou de operar. $O$ processo de decisão referente à política industrial foi concentrado em unidades que tratam de políticas de estabilização, em especial os Ministérios do Planejamento (SEPLAN) e Fazenda (MF), revelando a prioridade dos objetivos de estabilização sobre os de política industrial. O Ministério da Indústria e Comércio e órgãos como o Conselho de Desenvolvimento Industrial perderam o poder que detinham na época do II PND.

Especificamente em relação à política de comércio exterior, apenas um órgão formulador de política industrial, a CACEX, conservou um papel expressivo. Todavia, subordinado à política do MF, pois a articulação da política de exportações foi feita via CMN-CONCEX-MF-BEFIEX-CACEX, o que dava um horizonte de curto prazo para o programa de exportações, já que estes órgãos eram praticamente dominados pelo MF. Também as metas da política de importações eram estabelecidas em função da necessidade imediata de geração de excedentes comerciais.

Para concluir, pode-se dizer que o processo de substituição de importações no Brasil aproveitou a existência de escalas no mercado interno para prosseguir no processo de industrialização voltado para dentro com maior sucesso do que países pequenos. $O$ desejo de "independência nacional" encontrou um campo fértil nesta estratégia. $O$ crescimento do produto, da PTF e a intervenção de governo com conseqüientes ganhos microeconômicos até 1979 ajudam a explicar também a adesão empresarial pela continuidade deste arranjo institucional. ${ }^{34}$

Todavia, na segunda metade dos anos 70 , com o II PND, esgotam-se as oportunidades para a continuidade do processo de substituição de importações, de tal forma que os impactos positivos sobre o nível de investimentos e o crescimento do produto não mais serão significativos. Permanecem apenas as distorções da política comercial protecionista: o viés anti-exportação, que limita o crescimento da economia devido à necessidade de equilibrar as transações correntes; a ineficiência decorrente da baixa competitividade; o poder de fixação de preços dos oligopólios internos; o baixo estímulo à inovação e aos gastos com P\&D etc. Todos estes problemas, agravados pela crise do endividamento externo, se tornarão patentes no decorrer dos anos 80 , implicando uma necessidade de mudanças profundas na política comercial, que começa a ocorrer em 1990. 